\title{
The Recent Recession, the Current Recovery, and Stock Prices
}

As OF APRIL 2002 THE signs of economic recovery are sprouting like spring flowers. The United States has emerged from the short but painful winter that followed the burst of the asset bubble in early 2000 and the anxiety caused by the events of September 11 and the anthrax scare in the fall of 2001.

This report addresses the current state of the economy. What were the salient characteristics of the 2001 recession? What is the state of the economy today? How does the latest business cycle compare with earlier cycles? What are the initial conditions of and therefore the prospects for the recovery? What are the conditions of profits and equity markets? Although it is clearly too early to write the definitive economic history of the recent downturn, it is nonetheless useful to describe the terrain as it appears in early 2002.

\section{1: The Mildest Recession}

To begin with, it appears that the 2001 recession was extremely mild. Real GDP growth was close to zero in the second half of 2001, and unemployment rose relatively little. Was it really a recession? For that matter, what is a recession?

From the point of view of economic welfare, business downturns are undesirable, and therefore the subject of concern and study, because they

I am grateful for helpful suggestions from Ray Fair, George Hall, Ken Petrick, and members of the Brookings Panel. 
reduce the nation's output below its potential, reduce people's real incomes, and cause the economic pain of involuntary unemployment. The National Bureau of Economic Research (NBER) defines a recession as a period with "a significant decline in activity spread across the economy, lasting more than a few months, visible in industrial production, employment, real income, and wholesale-retail sales." ${ }^{1}$ Technically, a recession or contraction is a period of declining economic activity because the term refers to the slope of the economy's trajectory rather than its level relative to a high-employment benchmark. From an economic point of view, however, the levels of output, unemployment, and employment relative to a high-employment baseline are probably more important than their derivatives.

To gauge the severity of the 2001 recession compared with earlier ones, I first examine some of the fundamental variables involved in business cycles. Figure 1 shows a measure of business conditions that is designed to capture substantial declines in output. It shows an index that is zero if the economy is growing and equals the two-quarter growth rate of real GDP if that term is negative. The shaded areas are the NBER contractions (recessions). This measure is an accurate predictor of NBER recessions in that it calls every NBER recession and has no false positives. The latest recession barely sneaks in the door, however. The negative growth for 2001 is barely visible and is by a wide margin the smallest downward spike of any postwar recession.

A closely related indicator of cyclical conditions is total nonfarm employment. If we construct a series based on two-quarter employment growth rates (not shown) like that in figure 1, periods in which employment declined are also good predictors of NBER recessions. Job loss was substantial in the 2001 recession, but the series has a pattern very similar to that in figure 1 , with the 2001 recession virtually tying with the 1970 recession for the smallest postwar decline.

Figure 2 shows an analogous measure for the unemployment rate. Here the line shows increases in the four-quarter unemployment rate when unemployment is rising and is at zero when it is falling; recessions are again shown as shaded areas. This measure produces several false positives, indicating that the unemployment rate is a less reliable indicator of

1. NBER Business Cycle Dating Committee, March 11, 2002, at www.nber.org/cycles/ recessions.html. 
Figure 1. Recessions and Declines in Real GDP Growth, 1948-2001 ${ }^{\mathrm{a}}$



Source: Author's calculations based on data from Bureau of Economic Analysis, National Income and Product Accounts (NIPA).

a. Two-quarter growth rate of real GDP when negative and zero otherwise. Shaded areas indicate NBER-dated recessions.

NBER recessions than real GDP growth. A slight modification would hold that when the four-quarter change in the unemployment rate is greater than 1 percentage point, we have a reliable indicator of recession. By the unemployment rate standard, the last two recessions have been the mildest in postwar history.

A final indicator of business cycles is the output gap, which measures the percentage difference between potential and actual GDP. The analysis of gaps is controversial because of the difficulties in defining and measuring potential output. Some classical approaches hold that output is essentially always equal to its potential, so that output gaps either are definitionally zero or quickly disappear. Among schools that believe in gaps, some have measured the gap by interpolating between output peaks. Others use Okun's law and calculate the difference between actual output and the output that would be consistent with a benchmark unemployment rate such as the NAIRU; this in turn gives rise to other ambiguities about 
Figure 2. Recessions and Increases in the Unemployment Rate, 1948-2001 ${ }^{\text {a }}$

Percentage points

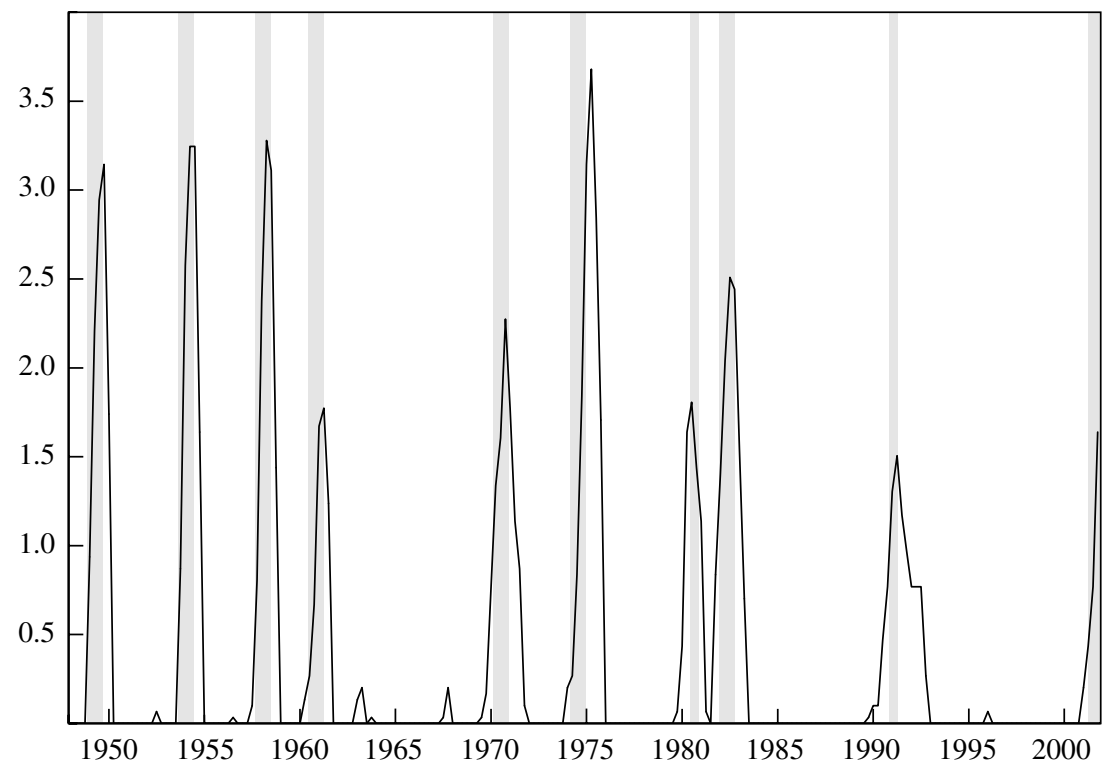

Source: Author's calculations based on data from Bureau of Labor Statistics.

a. Four-quarter change in the civilian unemployment rate when positive and zero otherwise. Shaded areas indicate NBER-dated recessions.

whether the NAIRU is a wage or a price NAIRU and to empirical difficulties in measuring the NAIRU.

For present purposes I use a NAIRU-based measure of potential output derived from estimates of potential GDP from the Congressional Budget Office (CBO). ${ }^{2}$ Figure 3 shows the output gap (again, only if positive) over the postwar period. This measure is particularly instructive because the gap measures the level of economic distress, whereas both figures 1 and 2 measure the rate of change of output or unemployment. Here again the 2001 recession is barely visible. It pales in size relative to the major downturns, in 1974-78 and 1980-85, associated with the two oil shocks. Thus, by the third test, 2001 was again the mildest recession in the postwar period.

2. I revised downward the estimated growth of potential GDP in the 1996-2001 period to 3.4 percent a year to reflect the most recent $\mathrm{CBO}$ estimates (CBO, 2002). 
Figure 3. Recessions and Real Output Gaps, 1948-2001 ${ }^{\text {a }}$

Percent of potential GDP

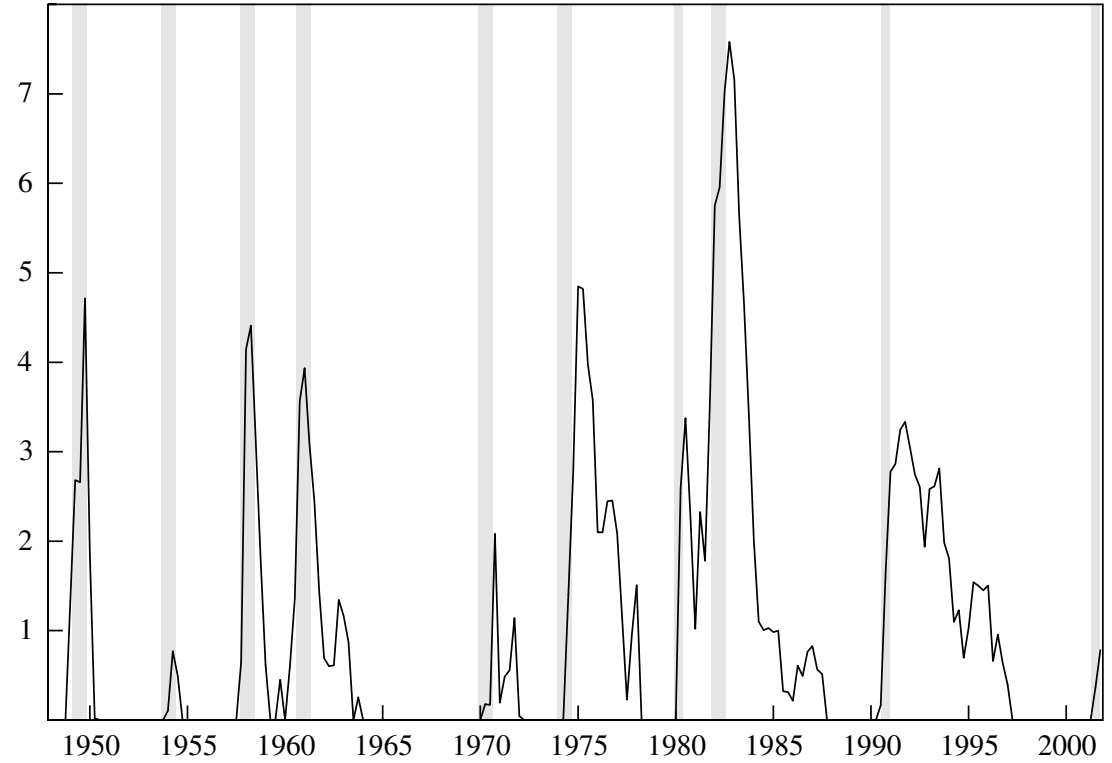

Source: Author's calculations based on data from Bureau of Economic Analysis, NIPA, and CBO (2001, 2002).

a. Percentage difference between potential GDP and actual GDP when positive and zero otherwise. Potential real GDP estimates through 1996 are from CBO (2001) and thereafter grow at a 3.4 percent annual rate, as assumed in CBO (2002).

\section{1: The Highest Trough}

A second unusual feature of the 2001 recession was that the level of output was relatively high as the economy emerged from recession. In other words, at the trough of the recession, which I assume was the fourth quarter of 2001, the gap between actual output and potential output was relatively small.

Figure 4 shows the estimated GDP gap at the trough of each postwar NBER recession, again assuming that the trough of the latest recession came in the fourth quarter of 2001. The results are striking. The trough of the 2001 recession was as close to potential output as in any postwar recession; only the 1954 recession showed as small a gap. Indeed, to a first approximation, the economy was at its potential at the trough of the 2001 recession. This striking fact indicates, first, that the recession was 
Figure 4. Output Gap at Trough of Recession for Ten Postwar Recessions ${ }^{\mathrm{a}}$

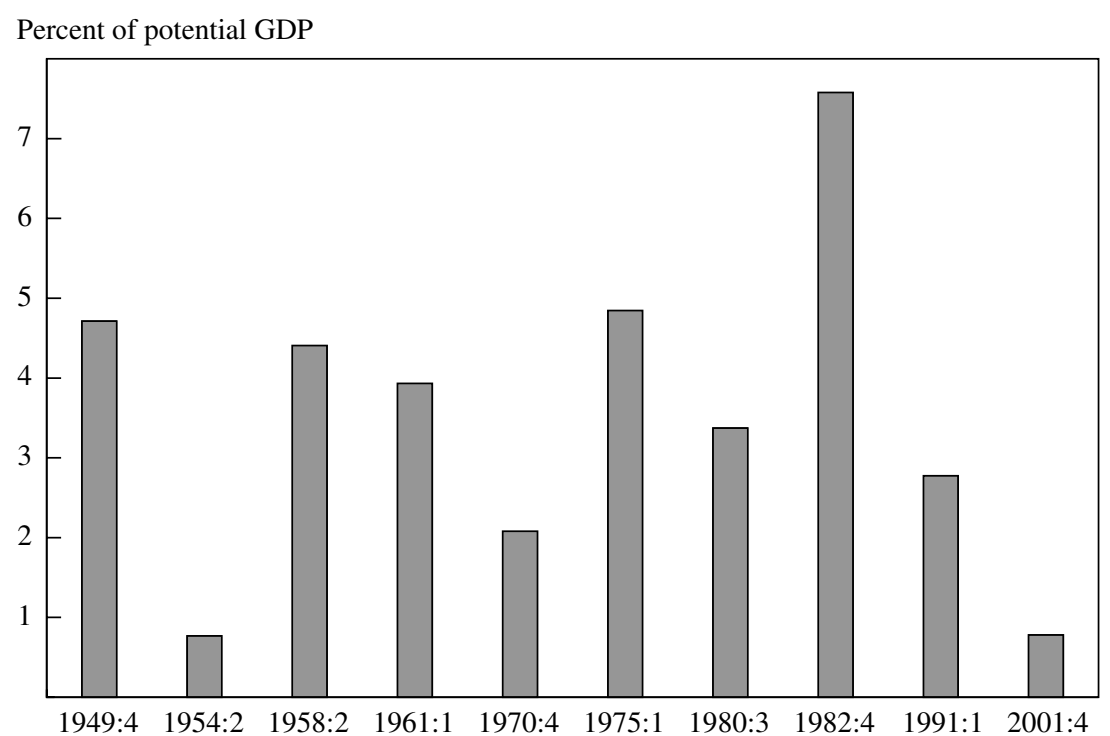

Source: Author's calculations based on data from the Bureau of Economic Analysis, NIPA, and CBO $(2001,2002)$. a. Calculated as the percentage difference between potential real GDP and actual real GDP. The potential GDP series is described in figure 3 .

indeed very mild, with only a small decline in output (as figure 1 showed) and, second, that it started from a peak at which output was extremely high and unemployment very low for a peacetime period. This point can be expressed in a different way, by noting that the unemployment rate in the fourth quarter of 2001 was 5.6 percent, close to most estimates of the current NAIRU, which cluster around 51/2 percent.

By contrast, the Federal Reserve Board's index of industrial capacity utilization does not corroborate this high level of factor utilization, but rather was close to the average for a recession trough at the end of 2001. However, industrial production makes up only a small slice of the economy-approximately 20 percent of GDP - and this slice consists largely of tradable goods for which domestic capacity utilization is increasingly irrelevant (oil production being the most obvious example). The most important limit on capacity is likely to be labor rather than manufacturing capital. Thus the low rate of capacity utilization is little comfort for those who worry about the inflationary risks that would be encountered if there were a brisk, defense spending-led recovery over the next few years. 


\section{Is It Time to Rethink the Definition of Recessions?}

By NBER business-cycle standards, the 2001 downturn, however mild, falls in the same category as the much deeper contractions of 1933 or 1982. This observation might well lead one to conclude that the traditional NBER business-cycle methodology, which identifies only peaks and troughs without reference to the depth or severity of the downturn, is outdated. This approach was reasonable given the meager and incomplete data available when Wesley Clair Mitchell and Arthur Burns invented the business cycle dating approach several decades ago. ${ }^{3}$ However, in light of the plentiful, timely, and comprehensive data available today, surely we can do better than simply flying a green flag or a red flag depending upon the slope of the underlying economic indicators. In this I am reminded of Tjalling Koopmans's critique of Burns and Mitchell more than a halfcentury ago: "[E]ven for the purpose of systematic and large scale observation of such a many-sided phenomenon [as business cycles], theoretical preconceptions about its nature cannot be dispensed with, and the authors do so only to the detriment of the analysis."

An alternative approach would be to develop quantitative criteria that would allow one to categorize business downturns in a manner analogous to the Saffir-Simpson hurricane scale. This suggestion in part reflects the finding that the volatility of output, along with the frequency and severity of business cycles, is declining in the United States. ${ }^{5}$ It also is based on the view that business cycles are more like hurricanes than like pregnancies: ${ }^{6}$ far from being a simple two-state phenomenon, they are extremely diverse in their shape, size, and duration. The proposal is in part motivated by the view that business-cycle dynamics are often grounded in local instabilities that can grow into full-scale disturbances if they are unchecked or trigger yet further instabilities.

As a start, I would propose categorizing recessions according to a scale of I (a pause in economic activity) to V (severe depression). Based on the

3. See in particular Mitchell (1913), which marks the beginning of the business cycle dating tradition. The most systematic study was that of Mitchell and Burns (1946).

4. Koopmans (1947, p. 163).

5. See Blanchard and Simon (2001).

6. The pregnancy, or two-state, view is associated with Hamilton (1990). A look at figures 1 through 3 , or a more systematic examination of the transition matrix between different states of the economy, would quickly reject the view that all recessions are a single state. 
size and duration of the declines in growth rates and gaps in output, employment, and unemployment, I would tentatively classify the historical recessions in the United States as follows:

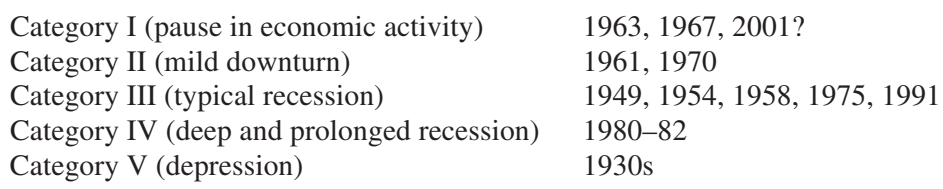

This "new view" of business cycles as heterogeneous in duration and severity would also allow us to view periods of recovery as highly differentiated. In the present recovery, which probably started in late 2001, there is little room for the economy to expand before it hits the inflationary danger zone. As a result, monetary policymakers are likely to hit the brakes sooner and harder than they did in earlier recoveries. And the stimulus package passed in March 2002 will be the latest exhibit for the argument that fiscal policy measures are generally implemented too much, too late, and with the wrong sign.

\section{Deciphering the Profits Numbers}

Part of the exhilaration of the 1990s was due to the rapid growth in corporate earnings. For the period 1992-2000, profits as reported in the National Income and Product Accounts (NIPA) grew at an average rate of 8 percent a year. Over the same period, earnings per share as reported by Standard \& Poor's grew at 15 percent a year.

Before digging into the concepts and numbers, it must be recognized that "profits" is a most elusive concept. There are at least four important definitions: profits for accounting purposes, profits for tax purposes, profits as measured in the NIPA, and economic profits. The first three are widely discussed, whereas the fourth is usually ignored. From the point of view of the corporation (rather than its shareholders), a reasonable definition of economic profits would be distributions to shareholders plus the change in real net worth from one period to the next. Such a definition differs from the other three measures of profits in important ways. Unlike economic profits, NIPA profits exclude real asset appreciation; accounting profits embody many concepts inappropriate to an economic definition, of which the treatment of depreciation and capital appreciation are 
two; and both tax and accounting profits treat capital gains inappropriately by excluding some accrued gains and including gains that are due only to price level changes.

In practice, the only available comprehensive measures of profits are NIPA profits and S\&P profits. Several versions of NIPA profits are available: NIPA profits after taxes exclude adjustments for inventory valuation and capital consumption, whereas NIPA adjusted profits after taxes include these adjustments. There are two published versions of S\&P profits. The first is operating earnings, which are more or less the earnings from continuing operations and exclude the impact of cumulative accounting changes, discontinued operations, extraordinary items, and special items; the second is earnings "as reported," which include these items. The earnings used in price-earnings ratios are the reported variant.

Although S\&P and NIPA profits are often compared, they differ substantially in their definitions, methodologies, source data, and coverage. ${ }^{7}$ I will highlight some of the major differences. First, the S\&P data cover only 500 large corporations, whereas the NIPA data cover the entire economy, even including very small subchapter S corporations. Second, NIPA profits are designed to measure the income from current production earned by domestic corporations, whereas $\mathrm{S} \& \mathrm{P}$ earnings are measured on a financial accounting basis. Third, NIPA profits exclude capital gains, which can be substantial; in 1998, for example, corporations reported $\$ 205$ billion of capital gains as part of their profits. Fourth, the S\&P data come from a changing panel of firms, which requires a complicated chaining procedure that ensures comparability of market value over time but does not ensure comparability of earnings. ${ }^{8}$

The fifth difference is seen in the capital consumption adjustment and the inventory valuation adjustment, which together measure the difference between economic cost and accounting cost. Although these series

7. Petrick (2001, pp. 16-20) provides a full discussion.

8. When firms enter or leave the S\&P 500 , continuity of the share price index is achieved by creating a total market "divisor" to link different periods together. If the priceearnings ratios of entering and leaving firms are unequal, this will induce a change in the price-earnings ratio of the aggregate. The procedure is discussed at www.spglobal.com/ 5sec3.pdf. An examination of the divisor suggests that firm substitutions are substantial. The divisor rises when new firms enter with higher value than the exiting firms, when companies issue new shares, or when two S\&P companies merge. The size of the divisor has grown by about 4 percent a year in the last decade, but there is no empirical evidence on the reasons for this growth. 
are generally quite smooth, the capital consumption adjustment jumped from $\$ 13$ billion to $\$ 186$ billion in the fourth quarter of 2001 ; this increase led to a huge difference between adjusted NIPA profits and S\&P earnings. A sixth difference is source data: the NIPA data are in principle derived from tax returns whereas the S\&P data are derived from financial accounts. On the other hand, early estimates of NIPA profits are based on financial accounts data, and they are often revised, whereas Standard \& Poor's apparently never revises its data or takes into account restatements of earnings.

Figure 5 shows these four measures of after-tax corporate profits over 1985-2001. The top two lines are NIPA profits after taxes, adjusted (the upper line) and unadjusted for capital consumption and inventory valuation (the second line from the top). The bottom two lines are operating (the second from the bottom) and reported after-tax earnings (the bottom line) of the companies in the S\&P 500. The data for the fourth quarter of 2001 show divergent trends in these profits numbers. After-tax adjusted NIPA profits increased 6 percent on a year-over-year basis, whereas the three other series declined by between 23 and 36 percent. The NIPA figures were affected by a one-time tax change arising from the March 2002 stimulus package, which allowed firms to expense 30 percent of covered investments. Because the source data for the NIPA are extremely sparse for the most recent period, it seems likely that the latest NIPA profits data will be significantly revised in the next few years.

All of the different profits series have taken a major dive in the last few years. As a share of GDP, the two NIPA series peaked in 1997 at just over 7 percent; since then their share has declined by about one-third, or by slightly more than 2 percentage points through the third quarter of 2001. The S\&P earnings share peaked three years later. The lag of S\&P earnings behind NIPA profits was not a feature of earlier cycles and has no obvious economic rationale.

What might have caused this most unusual pattern of earnings? The obvious suspicion is that the rapid rate of "innovation" in accounting techniques has distorted the timing of reported earnings over the last few years. Every day, the newspapers recount a host of new techniques by which companies have bolstered reported earnings. Some of the most egregious examples of these "Not Generally Accepted Accounting Principles," or NGAAP, include swapping capital assets such as natural gas futures contracts (Enron) or "dark" fiber optic networks (Global Cross- 
Figure 5. Alternative Concepts of After-Tax Corporate Profits, 1985-2001

Billions of dollars a year

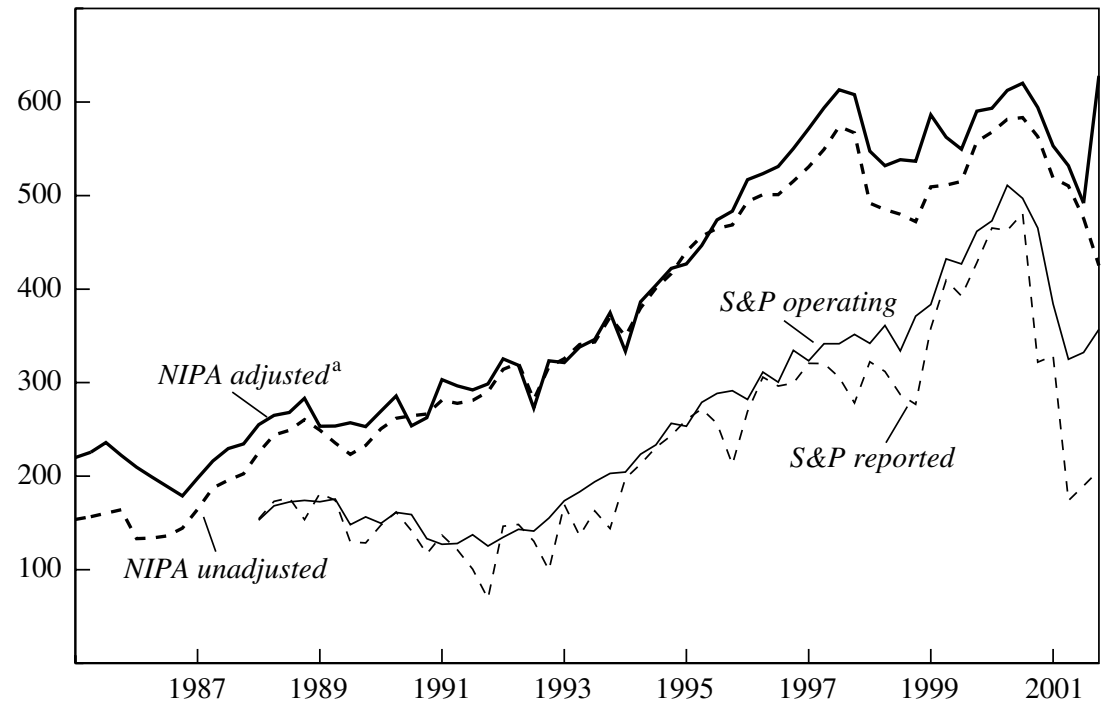

Source: Bureau of Economic Analysis, NIPA, and Standard \& Poor's.

a. Includes inventory valuation adjustment and capital consumption adjustment.

ing, Qwest, Enron) and capitalizing the outflow while recognizing the inflow as current revenue; increasing the salvage value of trucks over time (Waste Management); recognizing the returns to pension plans as operating income (IBM); recording sales of products still in research (McKesson HBOC); changing the pattern of accounting revenue from rentals (Xerox); increasing the value of the unused capacity of landfills even as they fill up (Waste Management); reporting happy pro forma numbers when the reality is unpleasant (Amazon.com, Yahoo, and Qualcomm among a crowd of other dot-coms dead and alive); using funds set aside as merger and acquisition reserves to increase operating income (Cendant); and doubling earnings by simply neglecting to include expenses (BroadVision). ${ }^{9}$

9. The Securities and Exchange Commission's report on its analysis of Waste Management's NGAAP was highlighted in the New York Times (Kurt Eichenwald, "Waste Management Executives Are Named in S.E.C. Accusation," March 27, 2002, p. C1). Swaps of "dark" fiber optic capacity were also described in the New York Times (David Barboza and Barnaby J. Feder, “Enron’s Swap with Qwest Is Questioned,” March 29, 2002, p. C1). 
Aside from enrichment of the few and depleted pension plans of the many, did NGAAP affect the aggregate numbers? Figure 5 suggests that NGAAP earnings have indeed infected total reported S\&P earnings. It seems clear that the peak in S\&P earnings lagged behind the peak in NIPA earnings because companies were "managing" their earnings (in this context, preventing an accounting decline in earnings). However, they could only prevent the earnings decline for a couple of years, after which they ran out of gimmicks, or the accountants-or else analysts and the Securities and Exchange Commission—began to blow their faint whistles.

Another interesting feature of the recent profits data, also shown in figure 5 , is that reported profits are currently extremely low relative to operating profits. The difference between reported and operating profits is primarily one-time charges that companies take to correct for past business or accounting errors-as they hang out their dirty laundry, so to speak. The declining ratio of reported to operating profits late last year probably reflects the tendency of companies to purge their earnings and balance sheets of questionable elements in light of the Enron scandal. The size of the write-downs became truly enormous in late 2001 and early 2002. Announced or estimated write-downs so far include $\$ 54$ billion for AOL Time Warner, $\$ 20$ billion to $\$ 30$ billion for Qwest, $\$ 15$ billion to $\$ 20$ billion for WorldCom, $\$ 10$ billion for VeriSign, $\$ 5$ billion for AT\&T, $\$ 3$ billion for Cisco, and the list goes on. Analysts are bruiting about a total price tag of $\$ 1$ trillion for the Great Balance Sheet Purge of 2002. ${ }^{10}$

In considering future earnings prospects, one must take into account both the cyclical depression of profits and the likelihood that reported profits are contaminated by an accounting purge. Figure 6 shows the historical trend in the ratio of quarterly $\mathrm{S} \& \mathrm{P}$ (reported) earnings per share to GDP and unadjusted NIPA earnings to GDP, where both are scaled so that the average ratio over the 1949-2001 period equals 100. Again, NBER recessions are shown as shaded areas.

The two series in figure 6 move together during most of the period until 1990. Since 1990 the pattern looks quite different, with the NIPA numbers largely skirting the 1991 recession. The most dramatic difference

10. "Buying Binge Could Cost Corporate America \$1 Trillion," USA Today, April 5, 2002, p. 1B. 
Figure 6. Trends in NIPA and S\&P 500 After-Tax Profits Relative to GDP, 1949-2001

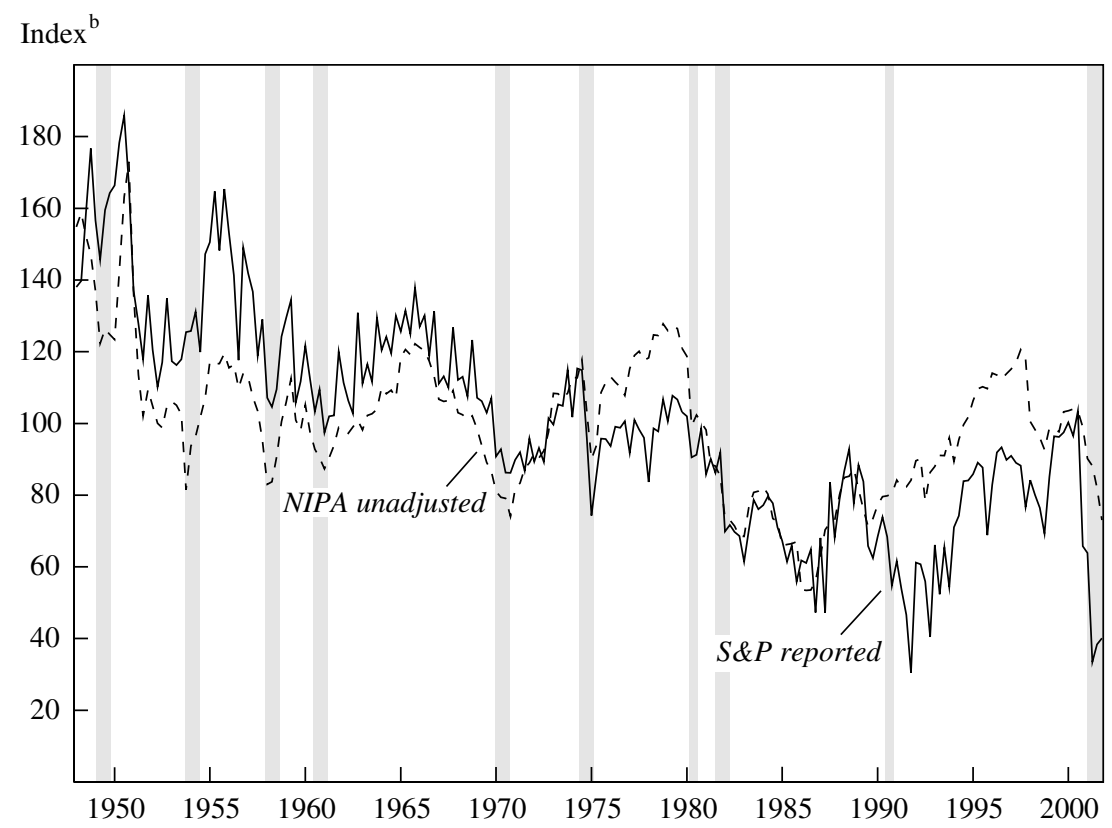

Source: Author's calculations based on data from Bureau of Economic Analysis, NIPA, and Standard \& Poor's. a. Shaded areas indicate NBER-dated recessions.

b. Each series is divided by GDP and scaled so that the average of the new series is 100 over 1949-2001.

comes at the end of the period, with the huge drop in reported S\&P earnings, presumably due primarily to the balance sheet purge.

To obtain a more realistic estimate of earnings than the reported S\&P earnings, I have calculated a series of S\&P earnings corrected for the business cycle and accounting purges. This series, which I call "corrected S\&P earnings," was calculated from a regression of the logarithm of S\&P reported earnings on the logarithm of unadjusted NIPA profits after taxes, time, a cyclical variable, and a constant. I then forecast corrected S\&P earnings by assuming that unadjusted NIPA profits are set at their cyclically adjusted level and that S\&P profits are at the level forecast on the basis of cyclically corrected NIPA profits. In effect, this uses NIPA profits as a proxy for cleaned-up $S \& P$ reported earnings. I then forecast $S \& P$ profits for the period 2001:4 through 2002:4. The projection assumes that real GDP grows one-half percentage point faster than potential output 
during 2002. This procedure, along with recent and projected values of $\mathrm{S} \& \mathrm{P}$ profits, is described in more detail in appendix A.

This experiment indicates that reported S\&P earnings were indeed depressed at the end of 2001 for a combination of cyclical and accounting reasons. Reported S\&P earnings for 2001 were about 30 percent below the estimate of corrected, or "clean," S\&P earnings. If earnings were to rebound to their forecast corrected levels at the end of 2002, they would be 55 percent higher than their levels in 2001:4.

In summary, there has been a substantial fall in profits since their peak in the late 1990s. The recent pattern of profits suggests that financial finagling has infected the reported profits figure, and in particular the aggregate financial accounting numbers, in the last decade. Perhaps the best summary would be to recall the wisdom in John Kenneth Galbraith's saying that depressions catch what the auditors missed.

\section{Party Time Continues in Equity Markets}

Robert Shiller has argued, in his influential and exquisitely timed book, Irrational Exuberance, that equity prices in the 1990s got seriously out of line with economic fundamentals. ${ }^{11}$ In Shiller's most recent analysis with John Campbell, the bears of academe write:

We believe that our original testimony and article are even more relevant today [March 2001]. Valuation ratios moved up in the year 2000 to levels that were absolutely unprecedented, and are still nearly as high as of this writing at the beginning of 2001. Even allowing for the possibility that the economy and financial markets have undergone some structural changes, these ratios imply a stronger case for a poor stock market outlook than has ever been seen before. ${ }^{12}$

What has changed since then? The major developments since early 2001 have been the steep decline in earnings discussed in the last section along with a sideways movement of stock prices. To illuminate the Campbell-Shiller thesis, I have looked at the real return on equities and the yield spread between equities and safe assets. The basic assumption in this analysis is that the earnings-price ratio is a reasonable estimate of

11. Shiller (2001).

12. Campbell and Shiller (2000, p. 1). 
the forward-looking real return on equities, ${ }^{13}$ where this is defined as the expected total return per share (dividends plus capital gains) corrected for movements in the general price level.

The derivation of this result is presented in appendix B, but the reasoning can be described verbally. Begin with the market value of the firm, the assets of the firm, and the earnings or profits on assets. For this purpose, assets should include all tangible and intangible assets. Let $q$ be the ratio of the market value of the firm to its total assets, where marginal $q$ applies to new investments and average $q$ applies to old assets. It will simplify the discussion to assume that firms have no debt and to ignore taxes.

The conditions under which the prospective return on equity equals the earnings-price ratio are neither obvious nor obviously correct. To begin with, the theory needs to assume that earnings are an accurate measure of true profits, which definitely gets the exercise off to a bad start. One simple case where the earnings-price ratio is a good forward-looking estimate of the return on equities is that where marginal $q$ equals 1 , the $q$ ratios are constant, and the expected rate of return on capital is constant. Some other cases are discussed in appendix B. In reality, the $q$ ratios and the expected return on capital are likely to bounce around a great deal, and so the actual returns on equity will differ from the earnings-price ratio. In terms of market conditions in early 2002, the major reasons to believe that equity returns will differ from the earnings-price ratio are, first, if the rate of profit rises because it is currently depressed, and second, if average $q$ falls because assets are currently overvalued.

With these theoretical considerations behind us, figure 7 shows two variants of the estimated real forward-looking return on equities over the postwar period. Variant 1 is the earnings-price ratio for the S\&P 500 using quarterly earnings. ${ }^{14}$ Variant 2 takes variant 1 and performs the correction for the business cycle and for accounting problems discussed in the last section.

13. Other popular approaches sometimes compare the earnings-price ratio or the dividend-price ratio with nominal interest rates. These approaches make the fundamental error of confusing real and nominal magnitudes-in effect assuming that the prices of goods and dollar returns are constant.

14. The published measure of earnings in the $S \& P$ numbers (such as that used in calculating price-earnings ratios) uses a four-quarter trailing average of earnings. In the present analysis I take seasonally adjusted current quarterly earnings at an annual rate and divide this by the current-period stock price index. 
Figure 7. Alternative Measures of the Forward-Looking Real Return on Equity, 1950-2001

Percent a year

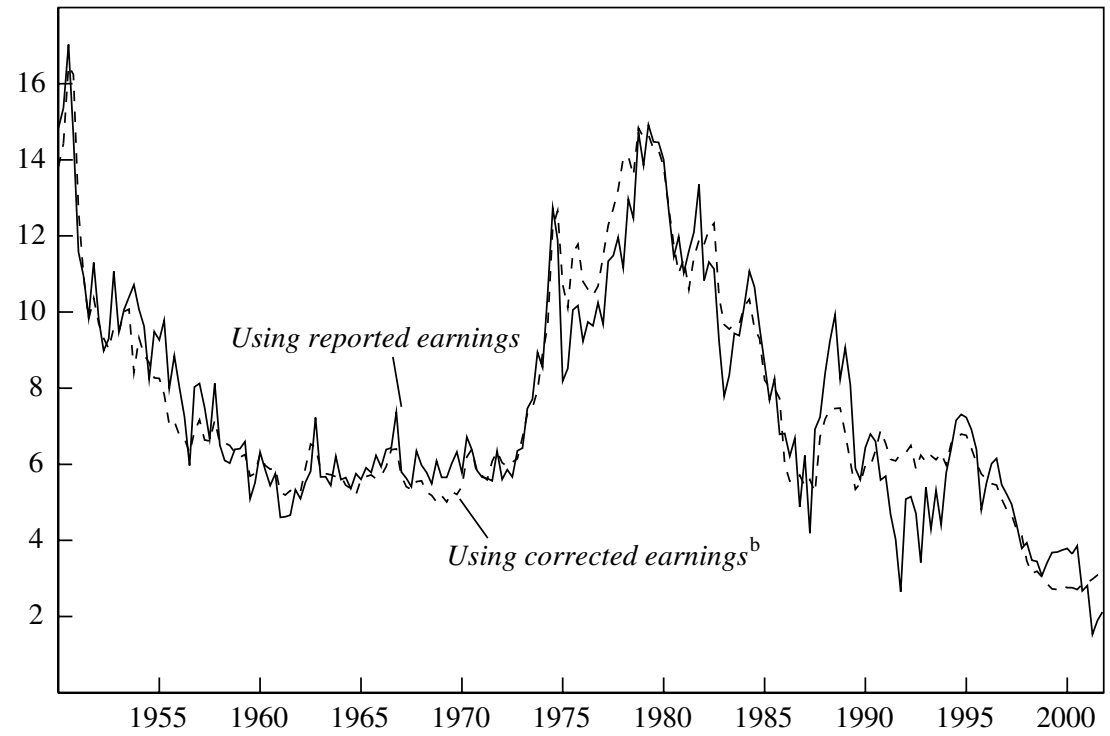

Source: Author's calculations based on data from Bureau of Economic Analysis, NIPA, and Standard \& Poor's. a. Quarterly earnings-price ratio for the S\&P 500, measured as reported earnings divided by the S\&P 500 index.

b. Corrected for cyclical fluctuations and accounting adjustments (described in text).

Both series tell the same story. The real yield on equities moved up and down during the postwar period and then declined continually after 1980. In 1980 the forward-looking yield was around 14 percent, and the actual annual return over the 1980-2001 period was 12 percent. The real yield on equities in 2001 was between 2 and 3 percent a year, depending upon which measure is used. The real forward-looking return on equities in 2001 was by a wide margin at the lowest level of the entire postwar period.

Although the real yield picture is interesting, a more fundamental question concerns the difference between the real yield on equities and the risk-free (or a safe) real rate of interest. For this calculation I took the risk-free real rate of interest to be the ten-year Treasury bond rate minus the four-quarter trailing rate of inflation for the chained price index for 
GDP. ${ }^{15}$ I call the difference between the real equity rate and the real bond rate the "equity spread," but others might call it the equity premium. Standard doctrine holds that the equity spread should be positively associated with the systematic risk of equities and should definitely be positive.

Figure 8 shows two different calculations of the equity spread over the last half century using the two series on the forward-looking return to equities from figure 7 . The story told here is slightly different from that in figure 7. The equity spread declined sharply in the early 1980s with the high real interest rates of that period. The spread then ranged between 2 and 4 percentage points in the late 1980s, and it has gradually declined since then. At the end of 2001, the equity spread was close to zero-either slightly negative if the uncorrected earnings figure is used or slightly positive if the corrected figure is used.

According to the most recent data, and focusing on the corrected series in figure 8 , the spread has moved up slightly since the peak of the equities market in the spring of 2000. In the first quarter of 2000, the spread between equities and bonds was a negative 157 basis points, whereas by the end of 2001 the spread had moved to a positive 47 basis points. For the latest period (mid-April 2002, not shown), bond yields have risen and the corrected equity spread has dipped back down to minus 30 basis points. ${ }^{16}$

15. Alternative approaches to measuring inflation would use the price index for corporate product or the consumer price index rather than the chained price index for GDP, and alternative interest rates would be the real short-term interest rate or Treasury real interest bonds. These would change the levels of the curves but would not change the general trend. For example, over the last five decades, the real one-year Treasury rate has averaged about 70 basis points less than the ten-year rate, and so the spread would be that much higher over the period. The average rate of inflation for the GDP price index was 0.3 percentage point lower than that for the consumer price index for the last five decades. This suggests that the estimated returns or spreads might differ by as much as 100 basis points a year if different indexes were employed.

16. Changes in the spread could arise from many factors. Changes in risk aversion, changing expectations of real growth in the returns on equities, and changing perceived riskiness of stocks are the fundamental economic factors (as distinguished from technical or psychological factors). Is seems hard to derive sound reasons why any of the three fundamental factors have changed so dramatically in favor of equities in recent years. It has been argued that the equity premium was excessive during most of the twentieth century, but no theory would predict a zero equity premium. Nor does it seem plausible that a model with a constant equity premium fits recent experience. 
Figure 8. Forward-Looking Spread between Equities and Bonds, 1952-2001 ${ }^{\mathrm{a}}$

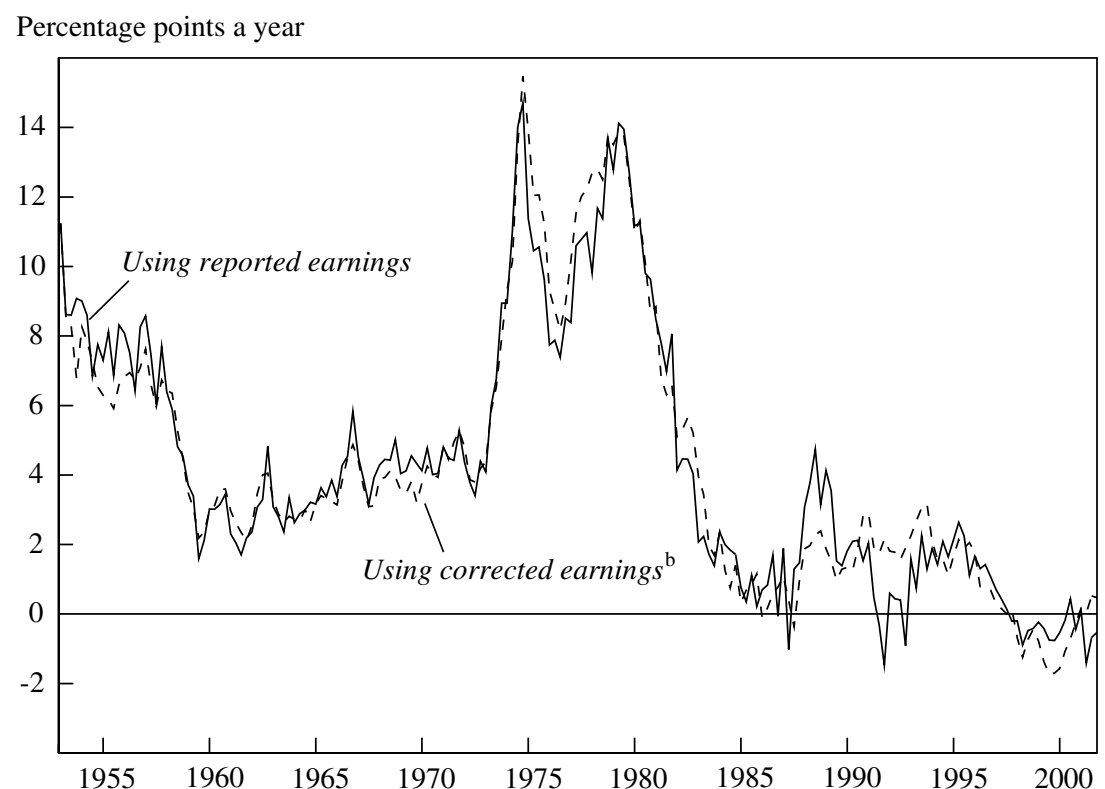

Source: Author's calculations based on data from Bureau of Economic Analysis, NIPA; Board of Governors of the Federal Reserve; and Standard \& Poor's.

a. Forward-looking return on equities (from figure 7) minus the real interest rate on ten-year Treasury bonds.

b. Corrected for cyclical fluctuations and accounting adjustments (described in text).

It is useful to compare these estimates with surveys of what economics and finance professors actually believe about the stock market's prospects. According to Ivo Welch's survey of 510 economics and finance professors conducted in August 2001, the average equity spread was estimated to be 3.4 percentage points for a one-year horizon and 4.7 percentage points on a thirty-year horizon. ${ }^{17}$ About 6 percent believed that the equity premium would be negative at a one-year horizon, and none believed that it would be negative at a thirty-year horizon. Clearly, neither Campbell and Shiller's writings, nor Shiller's book, nor actual earnings-price ratios have made much of a dent in the optimism of finance professors.

17. Welch (2001). The survey question was "I expect the average equity premium (i.e., expected return on the market net of the short-term interest rates) over the next 1 year to be. ..." The market was taken to be the S\&P 500 . 
The overall results suggest that the prospective yield on equities is about equal to that on safe assets. At the same time, the prospective real yield on equities is at its low point of the last half-century. The overvaluation of equities has improved slightly since Campbell and Shiller's last gloomy prognostication, but it hardly looks rosy.

\section{Summary}

The basic features of the current recovery are clear. The downturn of 2001 was extremely mild, somewhere between a category I and a category II recession on the economic hurricane scale. Because the economy began the recession at an unusually high peak, and because the downturn was short and mild, the economy at the trough of the recession (assumed to have occurred in late 2001) was close to full employment in terms of inflationary pressures.

Corporate profits are depressed relative to their peaks in the 1990s, and the forward-looking real return on equities is about equal to the risk-free real rate of interest, that is, the rate on medium-term U.S. government bonds. For those who make their living in financial markets, this is not good news. Bonds are likely to get hit quickly if the economy recovers sharply and the Federal Reserve follows its script of preempting inflationary output growth. Stocks are still overvalued relative to most of the postwar period-and this at a time of significant prospects of financial tightening and growing concern about what bad news still hides inside the black box of earnings statements. It seems unlikely that the United States will soon return to the bubbly days of the late 1990s.

\section{APPENDIX A}

\section{Derivation of Corrected $S \& P$ Earnings}

S\&P REPORTED PROFITS ARE affected both by the business cycle and by accounting fraud and low misdemeanors. To estimate a series of "clean," or corrected, S\&P profits, I use NIPA profits as a proxy variable. In what follows, $P_{t}$ is measured $\mathrm{S} \& \mathrm{P}$ profits, $P_{t}^{*}$ is true $\mathrm{S} \& \mathrm{P}$ profits, and $P_{t}^{* C C}$ is cyclically corrected true $\mathrm{S} \& \mathrm{P}$ profits. $N P_{t}$ and $N P_{t}^{C C}$ are NIPA unadjusted 
profits with and without a cyclical correction, respectively. Each cyclically corrected variable equals the uncorrected variable's estimated value at potential output.

The first step in deriving corrected earnings is to obtain cyclically corrected unadjusted NIPA profits after taxes. This is done by estimating the following equation from 1948:1 to 2001:4:

$$
N P_{t} / \mathrm{GDP}_{t}=a_{0}+a_{1} t+a_{2}\left(U_{t}-\mathrm{NAIRU}_{t}\right)+e_{1 t} .
$$

I then measure cyclically adjusted profits by removing the cyclical influence:

$$
N P_{t}^{C C}=\mathrm{GDP}_{t}\left[N P_{t} / \mathrm{GDP}_{t}-a_{2}\left(U_{t}-\mathrm{NAIRU}_{t}\right)\right]
$$

Next I estimate S\&P profits as a function of NIPA profits and a cyclical variable:

$$
\ln \left(P_{t}\right)=b_{0}+b_{1} \ln \left(N P_{t}\right)+b_{2} t+b_{3}\left(U_{t}-\mathrm{NAIRU}_{t}\right)+e_{2 t} .
$$

Adjusted S\&P profits are then determined by using the forecast from this equation with NIPA profits at their cyclically corrected levels:

$$
\ln \left(P_{t}^{* C C}\right)=b_{0}+b_{1} \ln \left(N P_{t}^{C C}\right)+b_{2} t
$$

Recent values of reported and adjusted S\&P earnings per share are given in table A1.

APPENDIX B

Relationship of Earnings-Price Ratios to the Prospective Real Return on Equities

THIS SECTION DERIVES the statements in the main text concerning the relationship between the forward-looking real return on equities $\left(r^{e}\right)$ and the earnings-price ratio $(e / p)$. 
Table A1. As-Reported and Corrected S\&P Earnings per Share, 1999-2002 Dollars

\begin{tabular}{lccc}
\hline Quarter & As reported & Corrected $^{\mathrm{a}}$ & Ratio (percent) $^{\text {(n) }}$ \\
\hline $1999: 1$ & 10.72 & 9.02 & 119 \\
$1999: 2$ & 12.23 & 9.06 & 135 \\
$1999: 3$ & 12.39 & 9.10 & 136 \\
$1999: 4$ & 12.86 & 9.65 & 133 \\
$2000: 1$ & 13.43 & 9.78 & 137 \\
$2000: 2$ & 13.18 & 9.97 & 132 \\
$2000: 3$ & 14.24 & 10.00 & 142 \\
$2000: 4$ & 9.13 & 9.73 & 94 \\
$2001: 1$ & 8.97 & 9.23 & 97 \\
$2001: 2$ & 4.72 & 9.20 & 51 \\
$2001: 3$ & 5.43 & 8.83 & 62 \\
$2001: 4$ & 5.70 & 8.40 & 68 \\
$2002: 1$ & n.a. & 8.50 & n.a. \\
$2002: 2$ & n.a. & 8.61 & n.a. \\
$2002: 3$ & n.a. & 8.71 & n.a. \\
$2002: 4$ & n.a. & 8.82 & n.a. \\
\hline
\end{tabular}

Source: Author's calculations based on data from Bureau of Economic Analysis, NIPA, and Standard \& Poor's.

a. Corrected for cyclical fluctuations and accounting adjustments (as described in text). Values for 2002 are forecast.

Let $q^{A}$ be average $q, q^{M}$ marginal $q, p$ the price per share, $k$ total assets per share, $r^{k}$ earnings per unit of asset per year, $r^{e}$ the total return on equities per year, and $d$ the dividend payout ratio. Assume that there are no bonds and no taxes. We consider the real value of the variables in periods $t$ and $t+1$.

To begin with, the earnings-price ratio in the first period is equal to the ratio of the return on assets to average $q$ :

$$
e_{t} / p_{t}=r_{t}^{k} k_{t} / q_{t}^{A} k_{t}=r_{t}^{k} / q_{t}^{A} .
$$

To derive the total return on equities, note that the price per share in the first period is $p_{t}=k_{t} q_{t}^{A}$. Reinvested earnings are $\left(1-d_{t}\right) r_{t}^{k} k_{t}$, so that the price per share in the second period is

$$
p_{t+1}=k_{t} q_{t+1}^{A}+\left(1-d_{t}\right) r_{t}^{k} k_{t} q_{t+1}^{M} .
$$

The total return on equities between the first and the second period is then 


$$
\begin{aligned}
r_{t+1}^{e}= & {\left[d_{t} r_{t}^{k} k_{t}+k_{t} q_{t+1}^{A}+\left(1-d_{t}\right) r_{t}^{k} k_{t} q_{t+1}^{M}\right] / k_{t} q_{t}^{A}-1 } \\
& =\left(q_{t+1}^{A} / q_{t}^{A}\right)+\left[d_{t} r_{t}^{k}+\left(1-d_{t}\right) r_{t}^{k} q_{t+1}^{M}\right] / q_{t}^{A}-1 .
\end{aligned}
$$

One polar case is where marginal $q$ is 1 even though average $q$ is greater than 1 . This case would apply when the firm has supernormal profits in one area (say, on a patent or a piece of software) but is unable to leverage that market power into other markets. In this case, as long as average $q$ is constant, $r^{e}=r^{k} / q^{A}=e / p$. That is, the return on equities is the rate of return on existing assets divided by average $q$, which is the earnings-price ratio. This case is interesting because the return on equities diverges from the return on capital.

An alternative view would come about when marginal $q$ is different from 1. This case might apply for a firm that has been able to extend its monopoly into other markets. In this case, $r e=e / p$ when $d=1$, or where all earnings are paid out as dividends.

We can use numerical values to determine the forward-looking return for other cases. For large corporations, assume that the rate of return on assets is 8 percent a year after tax, average $q$ is 1.6 , and the dividend payout ratio is 0.5 . Suppose that marginal $q$ is 1.3 , which would imply that firms could project some but not all of their market power into new investments. Applying equation 3 then yields a forward-looking return of 5.8 percent a year, which exceeds the earnings-price ratio of 5 percent.

As a final case, assume that $q$ deviates from unity because of speculative bubbles or anti-bubbles, and that average $q$ regresses back toward 1 with a decay rate of 10 percent a year; that is, on average $q$ moves 10 percent of the way from $(q-1)$ to 1 each year. Then, using the same numbers as in the last paragraph, the forward-looking real return on equities would be 2 percent a year rather than 5.8 percent a year and would be below the earnings-price ratio.

The main point is that the forward-looking return on equities generally involves both average and marginal $q$. And where average $q$ is very high, the forward-looking return can be well below the rate of return on capital $r$. 


\section{Comment and Discussion}

George L. Perry: William Nordhaus's paper covers several related aspects of the current economic scene: the recent recession and current recovery, the behavior of profits during and leading up to the recession, and the prospects for the stock market in the recovery. He offers provocative ideas on all fronts.

Nordhaus compares the ten postwar recessions identified and dated by the NBER by examining four broad measures of economic loss: declines in real GDP, declines in employment, increases in unemployment, and positive output gaps as measured by the CBO. Output and employment declines track NBER-dated recessions very closely. Increases in unemployment lag these other measures of change, especially when measured over four quarters as in Nordhaus's figure 2, and this indicator yields several false-positive identifications of NBER recessions. The pattern of output gaps bears little relation to that of NBER recessions because these gaps usually remain positive for extended periods after a recession trough. However, if properly measured, the output gap would provide a summary indicator of overall economic loss.

From this broad-brush comparison of recessions, Nordhaus draws both a particular and a general message. The particular message is that last year's recession was the mildest of the postwar period and that at its trough, which he takes to be the fourth quarter of 2001, the economy was virtually at its potential output. I will say more about that later. The general message is that the NBER's approach to recession dating is outdated: recessions differ so much in their severity and length that a richer classification scheme is called for; meanwhile advances in economic science and 
data availability allow us to do a better job of classifying recessions than the pioneers of business cycle measurement were able to do. Nordhaus suggests developing quantitative criteria that would allow business cycle downturns to be classified more like hurricanes are, with several gradations reflecting their severity.

Nordhaus gives the impression that a lot is at stake in refining our definition of recessions and applying more data to the task of identifying and classifying them. He hints that business-cycle dynamics could reflect the propagation of small impulses into large outcomes, so that identifying incipient virulent recessions would have important benefits. As a scientific matter, that is an important question and related to the more general question of whether periods of recession are special, in the sense that agents respond differently in recessions than at other times. That would be a reason to care a lot whether we were in or heading for such a period. If we could predict emerging weakness better, we should. But that goal is and always has been hotly pursued. It has nothing to do with classifying downturns according to severity after the fact.

Turning to that more modest task, I agree with Nordhaus that the NBER should look not only at changes in but also at levels of economic activity in identifying recessions. And that criticism holds true even if we do not expand the NBER dating committee's limited mandate, which is to identify "a significant decline in activity spread across the economy" (emphasis added). I have always believed that one strength of recession dating by a committee of experts was that they were free to consider any and all evidence of recession. There were surely stretches in the first half of the 1930s when employment rose, but we all speak of that whole period as the Great Depression. And if we took away several months of dead-cat bounce in the economy that followed its precipitous decline in the first half of 1980, the whole of 1980-82 would be one recession, not two as judged by the NBER. It felt like one recession at the time. I see no reason other than precedent for the experts to look only at whether measures such as sales and employment are falling in identifying when a recession starts and, more important, when it ends.

However, going from principles to practice, I find the CBO output gap that Nordhaus uses in analyzing the level of economic utilization to be inadequate. The main problem is that empirical estimates of the NAIRU are the anchor for estimating potential output and the output gap, and those estimates are not reliable. The best thing Alan Greenspan has done 
as Federal Reserve chairman was to distrust the conventional wisdom in 1995 about what unemployment rate was too low. I would have thought that experience, along with some really good papers on the subject, would have persuaded Nordhaus to distrust the NAIRU estimates, too. An additional problem in judging the room for expansion today is the uncertainty about how fast the productivity trend is rising.

What other issues does Nordhaus raise or imply? The recent recession was marked by unusually good productivity gains, and therefore employment was weak relative to output. How to weight the two in identifying recessions is open to disagreement, but it is not a matter of applying more science. My sense of what we are after would look at both employment and unemployment. Nordhaus's more nuanced approach might favor output, since it does not end with a simple yes or no on recession.

Another issue that Nordhaus raises about NBER dating is its timeliness, but I find this overdone. The Federal Reserve does not wait for the NBER when it decides whether to act. So the dating committee need not overly concern itself about when we knew we were in trouble in real time, but rather about when, as a matter of history, to identify the turning points. After all, that is what NBER dating is mainly about, and it provides a useful way to organize ideas and present results. The deliberate speed with which the committee makes its judgments is appropriate for that purpose. Some people think that identifying a recession or a recovery has political consequences, but I doubt it. President George Bush, Sr., was in trouble in 1992 not because the NBER had not announced that the recession was over, but because unemployment was still rising as he campaigned, and he was seen as not caring much about it.

Nordhaus's particular message about last year's recession is consistent with how he views current economic prospects. Because the recovery starts with unemployment very near his estimated NAIRU, he sees little room for the economy to expand. He concedes that capacity utilization rates tell a different story, but he reasons that labor rather than capital will be the limiting factor and that any rapid expansion led by defense spending will soon run into rising interest rates from the Federal Reserve. As I see it, however, employment has fallen a lot, at the trough the economy was far from its potential, and ample spare capacity is just what rising defense spending needs. The Federal Reserve might raise rates before long. But since that is what it usually does, it might not surprise markets or have much effect on long-term rates if it did. 
Nordhaus turns to the behavior of corporate profits as another special feature of the present situation. The difference between S\&P operating profits and NIPA profits has fluctuated wildly since 1997, and Nordhaus provides a colorful discussion of what he calls "NGAAP accounting," which must surely account for much of this fluctuation. But puzzles remain. The rise in NIPA relative to S\&P profits in 1996-97 seems unlikely to have come from the accounting tricks that are probably the major factor in the relative rise of $\mathrm{S} \& \mathrm{P}$ profits in the following two years. S\&P earnings can be distorted by the changing sample of firms, and I would guess that the relative shortfall of S\&P earnings in this period reflects the introduction, at large market value weights, of Internet-related firms with negative earnings. The relative decline in NIPA earnings in the next couple of years may reflect the exercise of stock options, which are counted as a compensation cost in the NIPA. As to the relative collapse of S\&P profits after early 2000 , that pattern fits the story that accounting tricks that raise profits in one period lead to a reckoning down the road.

I take two messages from all this. The first is that NIPA profits are by far the more reliable time series, in part because it is more risky to fool the Internal Revenue Service than to fool shareholders and analysts. The second is that we cannot hope to estimate the discrepancy between the two. So how do NIPA earnings look today? In past business cycles, the share of profits in GDP has regularly peaked well before the economic downturn, a pattern that could be decomposed into wage, price, and productivity dynamics. So if there is a surprise this time, it is that the strong productivity growth of the late 1990s did not interfere with this regularity. But even if the present cycle is not atypical, the last two quarters of 2001 should be viewed with care. Third-quarter profits were depressed sharply by a bulge in capital consumption allowances, which I assume was associated with losses from the destruction of the World Trade Center. And fourth-quarter profits were boosted by retroactive accelerated depreciation from last year's tax bill. In addition, in the wake of the Enron-Andersen scandals, there may be an unusual amount of cleaning up of corporate accounts taking place, which could continue to depress profits temporarily.

Nordhaus concludes with a decidedly gloomy assessment of the prospects for equities. Although it is taking a cheap shot to question anyone's stock market forecast, since so much of stock price movement is unpredictable, I will discuss Nordhaus's forecast because he has laid out 
its underpinnings in a useful way, and they are worth examining. Consistent with his view that the expansion is starting with the economy already near its potential, he anticipates a very modest rate of recovery for the economy. I have already indicated that I do not trust those NAIRU-based estimates of potential or the limits to expansion that they imply, so I find his economic expectations too conservative.

Using an equation that allows for cyclical factors in recent profit levels and that attempts to adjust S\&P profits to recent NIPA profit behavior, Nordhaus then estimates the near-term growth of S\&P profits that would accompany such a modest economic recovery. He then embeds these profit estimates in a model of the spread between the expected real return on equities, measured by the S\&P price-earnings ratio, and the real return on Treasury bonds. He finds that this spread is near zero, which, he notes, is little changed from when John Campbell and Robert Shiller offered their most recent gloomy appraisal of equities in March 2001.

Nordhaus's equity spread model is very pretty, but I find it hard to drive. His figure 8 shows that the equity spread has varied from zero or a little below to over 14 percentage points. Large swings between optimism and pessimism may appear again. However, I find it plausible that the growing importance of retirement accounts and mutual funds has reduced the risk that many investors perceive in owning stocks and reduced the equity spread that we can expect to observe on average over a long period. And I find it probable that profits will rebound strongly from recent levels. That does not mean this decade's stock market will resemble the last decade's. Once-in-a-lifetime events do not happen often. But it makes it unlikely that we are now at the edge of a cliff.

General discussion: Robert Hall agreed with Nordhaus that the decline in output has been modest in the 2001 recession. He pointed out that the recession was about average in severity when judged by events in the labor market, as Nordhaus's figure 2 confirms. The NBER's Business Cycle Dating Committee has studied the divergent movements of output and employment carefully in this episode-such growth of productivity during a recession is unprecedented. Nonetheless, the committee has concluded that the episode is properly considered a recession by the traditional criteria of the NBER. Hall commended Nordhaus's categories for the severity of recessions, but he did not believe it should have a role in the NBER's procedures. The framework of the NBER is to maintain a 
chronology that assigns dates to peaks and troughs of economic activity. A recession is the period between a peak and a trough. Hall disagreed with Nordhaus's tentative assignment of the 2001 recession to the mildest category. He would place the recession in category III in terms of the movements of employment (which he personally believes is the most important indicator) and possibly in category II in terms of measures related to output.

With respect to Nordhaus's discussion of the stock market, Hall disagreed with Nordhaus's proposition that the earnings-price ratio measures the forward-looking return on equities. This view rests on the notion that the stock market values plant and equipment and other investments at their acquisition cost only. According to the standard view in financial economics and on Wall Street, embodied in the Gordon dividend formula, the earnings-price ratio forecasts the difference between the required rate of return and the growth of earnings over and above that coming from retained earnings. To the extent that firms have sources of earnings growth other than investments that are only worth their price, there is no puzzle about an earnings-price ratio that is below safe returns. Firms could have monopoly positions that grow in value, or they could earn growing streams of income on past inventions. For example, eBay's earnings-price ratio of only 0.7 percent does not mean that eBay will only return 0.7 percent to its shareholders. Rather, it embodies the belief that eBay's entrenched position in the online auction market will generate healthy growth of earnings for many years to come.

Robert Gordon emphasized that an NBER recession is understood as a period of broad decline in economic activity. This implies that declines in output are more relevant as a recession indicator than declines in employment. Growth recessions, as that term is commonly used, are periods when output grows slower than trend for a sustained period. Since changes in unemployment are related to changes in output relative to its trend, changes in unemployment are not useful in identifying NBER recessions. The level of unemployment is even less relevant. Gordon noted that unemployment had reached its low point well before the start of the 2001 recession and that it had continued to rise long after the end of the 1990-91 recession. He remarked that the recession in 2001 had been exceptionally mild and came very close to being a growth recession rather than an NBER recession. This, in turn, reflected the unusually strong productivity growth during 2001. Gordon regarded these productivity gains 
and the sharp decline in profits that came with them as the two big puzzles in the present cycle.

Martin Baily remarked that some aspects of economic performance since 2000 resembled a typical recession but that others did not. For six quarters after mid-2000, GDP growth slowed to well below its trend rate; thus the period qualified as a clear growth recession. But GDP declined only in the last of those quarters. (It was not the last quarter but the penultimate quarter, 2001:3, when the decline occurred.) In contrast, manufacturing production fell steadily over the same six quarters, and steeply for a brief period starting in September 2001. This manufacturing decline, together with the decline in total employment since the spring of 2001, looked more like a typical NBER recession, as did the large inventory cycle that occurred. Looking at the income side of the economy, Baily observed that labor income was strong relative to profits and that compensation of individuals at the top of the income distribution was rising as a share of total labor income. He offered two conjectures on the weakness in profits: one was that high-income workers were able to extract large increases in compensation despite the overall softening in the economy, and the other was that intense competition both at home and from abroad kept firms from reaping profits from the solid productivity advances. He added that these same competitive forces might have contributed to the unusually strong productivity in this period.

Alan Blinder pointed out that the NBER concept of a recession was not a useful measure of distress for countries like Singapore with their rapidly rising productivity trend. For such countries a growth recession is a more relevant concept of a weak period, because employment declines. Similarly, if U.S. productivity has speeded up considerably, the United States may experience NBER recessions only rarely in the future. Blinder urged the NBER to consider reviving the concept of growth recessions, which the United States had unambiguously experienced starting in mid-2000, because they may now be the relevant measure of economic distress. 


\section{References}

Blanchard, Olivier, and John Simon. 2001. "The Long and Large Decline in U.S. Output Volatility." BPEA, 1:2001, 135-64.

Campbell, John Y., and Robert J. Shiller. 2001. "Valuation Ratios and the LongRun Stock Market Outlook: An Update." Cowles Foundation Discussion Paper 1295. Yale University (March).

Congressional Budget Office. 2001. CBO's Method for Estimating Potential Output: An Update. Washington: U.S. Government Printing Office.

. 2002. The Budget and Economic Outlook: Fiscal Years 2003-2012. Washington: U.S. Government Printing Office.

Hamilton, James D. 1990. "Analysis of Time Series Subject to Changes in Regime.” Journal of Econometrics 45(1-2): 39-70.

Koopmans, Tjalling C. 1947. "Measurement Without Theory." Review of Economics and Statistics 29(3): 161-72.

Mitchell, Wesley Clair. 1913. Business Cycles. Berkeley, Calif.: University of California Press.

Mitchell, Wesley Clair, and Arthur F. Burns. 1946. Measuring Business Cycles. New York: National Bureau of Economic Research.

Petrick, Kenneth. 2001. "Comparing NIPA Profits with S\&P 500 Profits." Survey of Current Business (April): 16-20.

Shiller, Robert J. 2000. Irrational Exuberance. Princeton University Press.

Welch, Ivo. 2001. "The Equity Premium Consensus Forecast Revisited." Cowles Foundation Discussion Paper 1325. Yale University (September). 